\title{
Jealousy Induction Methods, Sex, and the Big-5 Personality Dimensions
}

\author{
Jennifer L. Weinstein, T. Joel Wade \\ Bucknell University, Department of Psychology, Lewisburg, USA \\ Email: jwade@bucknell.edu \\ Received April 30 ${ }^{\text {th }}$, 2011; revised June $3^{\text {rd }}$, 2011; accepted July $14^{\text {th }}, 2011$.
}

\begin{abstract}
One-hundred and twenty five participants were administered an online survey to investigate: which type of cheating, emotional or sexual, is more likely to be used in an attempt to induce jealousy in a partner, which type of cheating is perceived as most effective for inducing jealousy, and whether or not the Big-5 personality dimensions are related to the choice of jealousy induction technique. Emotional cheating was hypothesized to be selected more often, and given a higher effectiveness rating, than physical cheating for inducing jealousy in a partner. Additionally, men were hypothesized to rate physical cheating as worse than emotional cheating while women were expected to rate emotional cheating as more hurtful. The results were partially consistent with the hypotheses. Emotional cheating was selected as the method to induce jealousy most often and was rated as the most effective way to induce jealousy. However, physical cheating was rated as more upsetting by both men and women. Additionally, Big-5 personality dimensions were not related to choice of jealousy induction method or reactions to physical or emotional cheating. The findings are discussed in relation to prior research.
\end{abstract}

Keywords: Jealousy, Personality, Cheating, Big-5

\section{Introduction}

Jealousy is defined as the negative emotional reaction experienced when a relationship that is vital to a person's selfconcept is endangered by a real or imagined rival (Harris 2004). In addition, jealousy is a reflexive emotion that tends to be more common among people who are in love and more common in relationships where a great deal of resources and time has been invested (Fleischmann, Spitzberg, Andersen \& Roesch 2005). While nearly every relationship encompasses some form of jealousy, approximately $20 \%-25 \%$ of respondents on a recent national survey reported having at least one sexual affair over the span of their life (Fisher, Voracek, Rekkas, \& Cox, 2008). However, affairs are not only of one type. There are several different types of infidelity. The present research focuses on two specific types of infidelity and jealousy: sexual and emotional.

Sexual jealousy is defined as a complex psychological system whose functioning is activated by a perceived threat to one's place in a sexual relationship (Daly \&Wilson 1992). In relationships, this is often considered the stereotypical "cheating" on a significant other, meaning having sexual relations with another person while involved in an intimate and longterm relationship with someone else.

Emotional jealousy, on the other hand, refers to when one feels threatened by a partner's emotional involvement with a third party, or someone other than their significant other. Emotional cheating can include thinking about, talking to, spending quality time with, or talking about inappropriate things with a member of the opposite sex in a way that is normally reserved for one's partner.

Jealousy is a useful emotion for relationships (Buss, 2000; Wade \&Walsh, 2008). From an evolutionary point of view, those who are deficient in expressing jealousy are at a disadvantage in terms of mate retention and reproduction (Buss, 2000; Wade \& Walsh, 2008). So, not surprisingly, since jealousy can be beneficial to relationships, individuals sometimes set out to induce jealousy in their partners. Fleischmann, et al., (2005) report two main reasons for why individuals attempt to induce jealousy in their partners. The first is as a relational reward, meaning jealousy is being induced as a technique to improve the relationship and help boost one's self-esteem. The second is as relational revenge, which is used to punish the partner, and gain control. But, are there sex differences in jealousy induction?

Prior research findings suggest that men display greater upset in response to a long-term partner's sexual infidelity, whereas women display greater upset in response to a partner's emotional infidelity (Shackelford, Michalski \& Schmitt, 2004). This sex difference is explained as a product of internal fertilization in women and male paternity certainty, and female parental investment concerns. Since fertilization occurs within a woman, if she is unable to provide sexual fidelity, a man's paternity may be threatened (Shackelford, Voracek, Schmitt, Buss, Weekes-Shackelford \& Michalski, 2004). Likewise, from a woman's perspective, it is important to have a partner who will invest long term, not only emotionally, but also in terms of resources, time and finances (Shackelford et al., 2004). Thus, when a man is diverting his attention from his female partner to a different woman (emotional cheating) it can be perceived as a huge threat for his significant other (Shackelford et al., 2004). With these findings in mind one might expect there to be sex differences in jealousy induction. However, Fleischmann, et al., (2005) report that the basic structure by which jealousy is induced in relationships is essentially the same for both men and women overall.

Clearly, based on the aforementioned research on sexual and 
emotional infidelity one can see that sexual and emotional access are important for men and women in relationships. In addition, based on the aforementioned research on jealousy induction one can see that inducing jealousy can be advantageous for relationships. However, while the aforementioned research findings are interesting, research has not ascertained whether individuals would use either sexual or emotional access related methods more often to induce jealousy. Specifically, would physical, i.e., sexual, or emotional methods of cheating be used most often to induce jealousy.

Sheets, Fredendall and Claypool (1997) report that jealousy is most often used in romantic relationships to motivate action to retain exclusive access to one's sexual partner. This report suggests that physical cheating would be used much more often, has a more immediate result, and is a more effective way to induce jealousy in one's partner. However, research examining physical hookups, more specifically research on the chemistry of kissing, shows that kissing is used as a mate assessment device, that it induces bonding, and that it increases sexual arousal and receptivity (Hughes, Harrison \& Gallup, 2007). In addition, physical activity with another person, including kissing, causes sexual excitement, and increases the flow of oxytocin which not only excites the partner, but is also used as a form of bonding (Hughes et al., 2007). The importance of the chemistry of attraction and initial bonding of partners has been well established both for long term as well as short term relationships (Hughes et al., 2007). So, it can be inferred that physical contact, even something as simple as kissing someone other than your partner, can have important effects and can lead to the termination of one's current relationship. With this in mind, emotional cheating may be used more often as a jealousy induction method. But, this has not been directly tested.

Additionally, research examining which method, physical or emotional cheating, is considered most effective for inducing jealousy has not been implemented. Since jealousy can be beneficial to relationships (Buss 2000; Wade \& Walsh, 2008), and so many individuals engage in infidelity (Buss \& Schmitt, 1993; Shackelford \& Buss, 1997) it is important to fill this void in the literature on jealousy. Therefore, the present research was implemented. Specifically, the present research set out to ascertain whether: physical or emotional actions would be chosen more often to induce jealousy in a partner, gender differences with respect to choice of jealousy induction method exist, and whether or not men and women's feelings and attitudes about types of jealousy induction actions differ, and whether discovering evidence of physical or emotional cheating on the part of a partner is more upsetting.

Since personality plays a role in many areas of life (Larsen \& Buss, 2002) and personality plays a role in mate selection and relationships (Botwin, Buss \& Shackelford, 1997) one might expect personality dimensions to be related to: the choice of jealousy induction methods, attitudes about jealousy induction, and reactions to finding evidence of cheating. However, Wade and Walsh (2008) did not find a relationship between Big-5 personality dimensions and reactions to infidelity or overall jealousy. So, personality dimensions may not be related to jealousy induction methods. But, this has not yet been investigated. Therefore, the present research also investigates this issue by exploring the relationship between personality dimensions and jealousy induction using a measure of the Big-5 per- sonality dimensions.

Gostling, Rentfrow and Swann (2003) point out that the Big-5 is a hierarchical model of personality traits with five factors representing personality at the broadest level where each bipolar factor (e.g., extraversion vs. introversion) summarizes more specific facets (e.g. sociability) which, in turn, subsume a large number of even more specific traits (e.g., talkative, outgoing). The Big-5 framework suggests that most individual differences in human personality can be classified into five broad, empirically derived domains labeled as Openness, Conscientiousness, Extraversion, Agreeableness, and Neuroticism (Gosling et al., 2003).

Since cheating may encompass deficits in emotional or sexual access on the part of a partner (Shackelford \& Buss, 1997) and can lead to either forgiveness or mate expulsion depending on the type of cheating that takes place (Shackelford, Buss, \& Bennett, 2002), the present research also examines the question of whether a lack of physical(sexual) access or emotional access, on the part of a partner, is more likely to lead to relationship termination.

\section{Hypotheses}

Based on the research cited above, it was hypothesized that emotional cheating would be chosen more often than physical cheating. Additionally, it was hypothesized that emotional cheating would be perceived as more hurtful by women than by men. It was also hypothesized that men would rate physical cheating as worse, and would be more likely to end a relationship due to a lack of physical(sexual) access, rather than due to a lack of emotional access, while the opposite would occur for women.

\section{Method}

\section{Participants}

One-hundred and twenty-one participants (35 male, 86 female) responded to an internet based questionnaire. Participant age ranged from 18 to $78, M=23.86, S D=9.10$.

\section{Procedure}

Participants were recruited via an internet listserv and the introductory psychology course at a small northeastern University. Participants at the University received partial course credit for taking part in the research. Other participants did not receive any compensation. Participants completed an online survey. They were asked to indicate their age, race, sex, whether or not they have ever been in a sexual relationship, their current relationship status, their sexual orientation, and if they were currently using a hormonal type of birth control. Also, participants were asked to answer nine questions exploring their feelings concerning emotional versus physical cheating and which type of cheating would upset them or their partner more. For the jealousy induction method of choice assessment participants received the following instructions:

Please think of a committed romantic relationship that you have had in the past, that you have now, or that you would like to have. If you and your partner were fighting and you were trying to make him/her angry and induce jealousy, you would 
hypothetically: (please circle one)

1) emotionally cheat (think about, talk to, spend quality time with a specific member of the opposite sex and begin to like them more than a friend: talk about things that you should only be talking about with your significant other)

2) physically cheat (hook up with the other person)

Next participants were instructed to "assume there was a problem in their relationship and to indicate how likely a lack of emotional versus a lack of sexual access and vice versa would lead to a decision to end the relationship" using a 7 point scale $(1=$ not very likely, to 7 = very likely). Participants were then asked to pick which of the 2 situations: "your partner is emotionally accessible, but not sexually accessible" and "your partner is sexually accessible but not emotionally accessible", is more likely to lead them to end their relationship. Next, participants were asked 2 questions regarding how effective they would consider physically cheating and emotionally cheating to be for inducing jealousy in their partner using a 7 point scale (1 $=$ not effective, to 7 = very effective). Then participants were asked to circle the type of cheating that they thought would be used more often to induce jealousy, physically cheating or emotionally cheating. Participants were also asked to circle the type of cheating, physical or emotional that they felt would upset them more. Next, participants were asked to indicate(circle) which type of cheating, physical or emotional, they thought would upset their partner more. Participants were then instructed to: "assume you and your partner have been together for a significant amount of time" and they were asked to indicate which of the following scenarios would upset them more:

1)You found in your partner's phone that they had been constantly texting another woman/man(of the opposite sex), and they were somewhat provocative texts

2)You found evidence that your partner is physically seeing someone else (ex went to dinner and a movie with another male/female that you did not know).

Participants were then presented with a short form of the "Big-5 personality dimensions (Gosling et al., 2003). They were asked to indicate how accurately the personality traits described themselves using a 7 point scale $(1=$ disagree strongly, to 7 = agree strongly). Lastly, participants were given a short form of the Marlowe Crowne Social Desirability Scale (Strahan \& Gerbasi, 1972). The split-half reliability of the Social Desirability Scale was .72 in the present research. Upon completion of all questions, participants were presented with a debriefing statement.

\section{Results}

Chi-square tests were computed to determine if there were any significant differences regarding responses to: jealousy induction method, and whether or not emotional cheating is more upsetting than physical cheating. No significant effects were obtained across sex of participant, current relationship status, or sexual relationship experiences. Also, no significant effects were obtained across birth control usage status for women. Participant age was not found to be correlated with any responses also.

A significant effect was obtained for the question that gave a brief scenario and asked participants to chose between emotional and physical cheating as a means of inducing jealousy in their partner, $\chi^{2}(123)=96.21, p<.0001$. One hundred thirteen participants chose emotional cheating while 6 participants chose physical cheating.

A marginally significant effect was obtained for the question asking which type of jealousy induction method, physical or emotional cheating, is used more often, $\chi^{2}(123)=2.94, p<.087$. Most participants selected emotional cheating as being used more, 71 versus 52 people for emotional and physical cheating, respectively.

A significant effect was also obtained for the question regarding which type of cheating by a partner would be more upsetting $\chi^{2}(123)=36.50, p<.0001$. More participants were upset by physical cheating than by emotional cheating, 95 versus 28 for physical and emotional cheating, respectively.

A significant Chi-square was also obtained for the question asking which type of cheating would upset your partner more, $\chi^{2}(123)=70.32, p<.0001$. One hundred and eight participants chose being physically cheated on while 15 participants chose being emotionally cheated on. A significant Chi-square was also obtained for the question that asked which type of incriminating evidence would be more upsetting, finding evidence of physical versus emotional cheating, $\chi^{2}(123)=6.84$, $<.009$. Finding evidence suggesting that physical cheating had taken place was chosen as being more upsetting, 76 versus 47 for finding incriminating physical or emotional cheating evidence, respectively).

A series of Mixed Model Repeated Measures ANOVAs with the social desirability scale sumscore included as a covariate were computed to examine the responses to the effectiveness of jealousy induction methods, and sexual and emotional accessibility questions. A 2 (sex of participant) x 2(effectiveness questions) mixed model repeated measures ANOVA revealed a significant effect for the questions, $F(1,118)=7.47, \mathrm{p}<.007$, eta $^{2}=.06$. Emotional cheating was rated as a more effective way to induce jealousy in a partner than physical cheating ( $M=$ 4.59, $S D=1.31$ and $M=4.42, S D=2.17$, for emotional and physical cheating, respectively). Additional mixed model repeated measures ANOVAs across sexual relationship experience, current relationship status, and birth control status for women did not reveal any significant effects.

A 2 (sex of participant) x 2 (access questions) Mixed Model Repeated Measures ANOVA revealed a significant interaction of sex of participant and access questions, $F(1,119)=19.62$, $p$ $<.0001$, $^{2}{ }^{2}=.14$. An independent samples T-test was computed to determine which question encompassed the sex difference. The T-test revealed a sex difference for the question: "your partner is sexually accessible but not emotionally accessible", $(t(121)=-5.31, p<.0001), M=3.33, \mathrm{SD}=1.71$, and $M$ $=4.77, \mathrm{SD}=1.20$, for men and women, respectively). Women rated a lack of emotional access as more likely to lead to a decision to terminate a relationship.

A 2(sexual relationship history) $\times 2$ (access questions) Mixed Model Repeated Measures ANOVA revealed a significant interaction of having been in a sexual relationship in the past and the access questions, $F(1,120)=7.73, p<.006$, eta ${ }^{2}=.06$. An independent samples $\mathrm{T}$-test revealed that people who have had sexual relationship experience differed significantly from those who had not, on the question "your partner is emotionally accessible but not sexually accessible" $(t(122)=2.74, p<.007, M$ = 3.95, versus $M=2.40$, for no sexual relationship experience 
and sexual relationship experience respectively). Individuals who had been in a sexual relationship in the past were more likely to terminate a relationship due to lack of sexual accessibility.

Additional Mixed Model Repeated Measures ANOVAs across current relationship status, or birth control usage status for women revealed no significant effects.

Correlations were computed to see which, if any, of the Big-5 personality dimensions were related to participants' responses. No significant correlations were obtained. Correlations were also computed to determine whether or not a sumscore for the Social Desirability scale was related to the responses to the categorical questions. No significant correlations were obtained for the Social Desirability sumscore. Lastly, correlations were also computed for age and responses to the scalar questions. Age of participant was not correlated with scalar responses.

\section{Discussion}

The current research set out to determine: whether or not individuals are more likely to use physical or emotional actions to induce jealousy in a partner, whether physical or emotional cheating is perceived as a more effective means of jealousy induction, whether or not there are sex differences in choice of jealousy induction method, attitudes towards inducing jealousy via emotional or physical methods, and whether or not the Big-5 personality dimensions are related to choice of jealousy induction method. It was hypothesized that emotional cheating would be chosen more often as the preferred method of jealousy induction and would be rated as a more effective means of jealousy induction. Additionally, it was hypothesized that emotional cheating would be perceived as more hurtful by women than by men. Lastly, it was also hypothesized that men would rate physical cheating as worse, and would be more likely to end a relationship due to a lack of physical(sexual access), rather than due to a lack of emotional access, while the opposite would occur for women.

The results obtained support the hypothesis that emotional cheating is used more often than physical cheating (113 participants chose emotional and 6 participants chose physical when asked which they would use to induce jealousy), since physical cheating often indicates the termination of relationships. In addition, emotional cheating was rated as a more effective means of inducing jealousy. Physical cheating was found to be more upsetting to participants than emotional cheating since this action suggests that the partner has made the choice to act upon their feelings, not just think about it. Why might this happen?

As stated in the introduction, research examining physical hookups, more specifically on the chemistry of kissing shows that kissing is used as a mate assessment device, that it induces bonding, and that it increases sexual arousal and receptivity (Hughes et al, 2007). In addition, physical activity with another person, including kissing, causes sexual excitement, and increases the flow of oxytocin which not only excites the partner, but is also used as a form of bonding (Hughes et al, 2007). Since the importance of the chemistry of attraction and initial bonding of partners has been well established in both long term, as well as short term, relationships (Hughes et al., 2007), one can infer that physical contact, even something as simple as kissing someone other than your partner, can have important effects and can lead to the termination of one's current relationship. This is in accordance with the data obtained as 95 participants said physical cheating would upset them more (28 participants chose emotional cheating), and that physical cheating would upset their partner more, as well (108 participants chose physical cheating and 15 chose emotional cheating when asked which would upset their partner more).

The previous explanation does not, however, support the idea that emotional cheating would be rated as more hurtful by women than by men, or that men would be more likely than women to break up due to a lack of physical(sexual) access. This pattern of findings may be because both sexes are more interested in long term mating (at least at some point in their life). Garcia and Reiber's (2008) research with college students supports this. Garcia and Reiber (2008) point out that even though college men and women engage in hooking-up, a form of short term mating, they desire long term relationships. So, while navigating sexuality can be a complicated process, at some point, it is instinctive to look for a long-term mate. Therefore, both sexes want the emotional and physical aspect to be present, and would both be equally upset by both types of infidelity, which concurs with Fleischmann, et al.'s, (2005) findings. This also can be explained by sexual strategies theory which points out that when men pursue a long-term mate, they will activate psychological mechanisms that solve the problem of paternity confidence (e.g. sexual jealousy and specific mate preferences) and that women use short term mating techniques to evaluate the prospect of a man being a long term mate (Buss \& Schmitt, 1993). Essentially, men and women are both looking for the emotional and physical aspect to be present, so they can ensure a fulfilling long term relationship in every aspect.

There was, however, a sex difference obtained when participants were asked how likely they were to break up if their partner was sexually accessible, but not emotionally accessible. Women were more likely to break up due to this deficit compared to men. This can be explained by women's mating preferences and parental investment. Women want the emotional access in terms of commitment on the part of a partner, which can lead to a long term relationship. Women have a greater parental investment since they bear and are often the primary caregivers for children that are produced. Thus, women need and want stability in terms of resources and emotions on the part of a partner, more so than do men do. This is consistent with the research showing that women are more likely to forgive physical infidelity, but not emotional infidelity (Shackelford et al., 2002). While women are sensitive to physical infidelity, "accumulating evidence suggests that women become more upset in response to a partner's emotional infidelity, which signals the long-term diversion of a partner's commitment and investment" (Shackelford et al., 2002). A woman's main concern with her partner's commitment should be with his ability to provide resources for their offspring, and emotional infidelity is often seen as a threat to his ability to provide these things (Buss, Larsen, Westen, \& Semmelroth, 1992; Wade, Palmer, DiMaria, Johnson, \& Multack, 2008).

The results for the Big-5 personality dimensions are consistent with Wade and Walsh's (2008) findings where Big-5 dimensions were not related to overall jealousy or reactions to a partner's commission of sexual or emotional infidelity. This 
leads one to infer that personality dimensions have no effect at all on jealousy induction and reactions to jealousy induction methods. However, while this is consistent with Wade and Walsh's (2008) research examining reactions to overall jealousy and infidelity, since the present research was the first study to examine this, additional research is needed to verify this inference.

\section{Conclusion}

The findings from the present research allow one to conclude that individuals prefer to use emotional methods to induce jealousy in a partner, and are more upset by a partner's commission of physical infidelity. Additionally, men are more likely to end relationships due to a lack of physical (sexual) access while women are more likely to end relationships due to a lack of emotional access. One can also conclude that age plays no role in these decisions since no significant correlations with age were obtained and there was an extremely large age range in this study (18 - 78 years old). The age finding is consistent with prior research examining jealousy. Prior researchers suggest that jealousy is a useful and functional relationship emotion. From an evolutionary point of view, one who lacks jealousy would be facing a shortcoming in terms of mate retention (Buss, 2000; Wade et al., 2008).

\section{Limitations/Future Study}

The present research used hypothetical situations, asking participants to put themselves in situations which they may not have been in before. Thus, one might assume that the ecological validity of the findings is not as strong as it could be if actual behavior was studied. However, Buss (2002) points out that hypothetical scenarios investigating reactions to relationship distress produce actual physiological responses. Thus, hypothetical scenarios such as those used in the present study may be good indicators of how individuals would actually behave/respond. Nevertheless, additional research investigating actual behavior, if possible, could add additional useful information.

The present research also used a short form of the Big-5 personality dimensions. Before one can conclude definitively that the Big-5 dimensions are not related to an individual's choice of jealousy induction method and reactions to jealousy induction additional research including a longer version of the Big-5 personality dimensions is warranted.

\section{References}

Botwin, M. D., Buss, D. M., \& Shackelford, T. K. (1997). Personality and mate preferences: Five factors in mate selection and marital satisfaction. Journal of Personality, 65, 107-136.

doi:10.1111/j.1467-6494.1997.tb00531.x
Buss, D. M. (2002). Human mate guarding. Neuroendocrinology Letters Special Issue, 23, 23-29.

Buss, D. M. (2000). The Dangerous Passion: Why Jealousy is as Necessary as Love and Sex. New York: The Free Press.

Buss, D. M., Larsen, R. J., Westen, D., \& Semmelroth, J. (1992). Sex differences in jealousy: Evolution, physiology and psychology. Psychological Science, 3: 251-255. doi:10.1111/j.1467-9280.1992.tb00038.x

Buss, D. M., \& Schmitt, D. P. (1993). Sexual Strategies Theory: An Evolutionary Perspective on Human Mating. Psychological Review, 100, 203-232. doi:10.1037/0033-295X.100.2.204

Daly, M \& Wilson, M. (1988). Homicide. New York: Aldine-de Gruyter.

Fisher, M., Voracek, M, Rekkas, V. P., \& Cox, A. (2008). Sex differences in feelings of guilt arising from infidelity. Evolutionary Psychology, 6, 436-446.

Fleischmann, A.A. (2005). Tickling the monster: Jealousy induction in relationships. Journal of Social and Personal Relationships, 22, 49-73. doi:10.1177/0265407505049321

Garcia, J. R., \& Reiber, C. (2008). Hook-up behavior: A biopsychosocial perspective. Journal of Social, Evolutionary, and Cultural Psychology, 192-208.

Gosling, S. D., Rentfrow, P. J., \& Swann Jr., W. B. (2003). A very brief measure of the Big-Five personality domains. Journal of Research in Personality, 37, 504-528. doi:10.1016/S0092-6566(03)00046-1

Harris, C. R. (2004). The evolution of jealousy. American Scientist, 92, 62-71.

Hughes, S. M., Harrison, M. A., \& Gallup, G. G. (2007). Sex differences in romantic kissing among college students: An evolutionary perspective. Evolutionary Psychology, 5. 612-631.

Larsen, R. J., \& Buss, D. M. (2002). Personality psychology: Domains of knowledge about human nature. Boston: McGraw-Hill.

Shackelford, T. K., \& Buss, D. M. (1997) Cues to infidelity, Personality and Social Psychology Bulletin, 23, 1034-1045. doi:10.1177/01461672972310004

Shackelford, T. K., Buss, D. M., \& Bennett, K. (2002). Forgiveness or breakup: Sex differences in response to a partner's infidelity. Cognition and Emotion, 16, 299-307. doi:10.1080/02699930143000202

Shackelford, T. K., Michalski, R. L., \& Schmitt, D. P. (2004). Upset in response to a child's partner's infidelities. European Journal of Social Psychology, 35, 489-497. doi:10.1002/ejsp.215

Shackelford, T. K., Voracek, M., Schmitt, D. P., Buss, D. M., WeekesShackelford, V. A., \& Michalski, R. L. (2004). Romantic jealousy in early adulthood and in later life. Human Nature, 15, 283-300. doi:10.1007/s12110-004-1010-z

Sheets, V. L., Fredendall, L. L., \& Claypool, H. M. (1997). Jealousy evocation, partner reassurance, and relationship stability: An exploration of the potential benefits of jealousy, Evolution of Human Behavior, 18,387-402. doi:10.1016/S1090-5138(97)00088-3

Wade, T. J., Palmer R., DiMaria, M., Johnson, C., \& Multack, M. (2008). Deficits in sexual access versus deficits in emotional access and relationship termination decisions. Journal of Evolutionary Psychology, 6, 1-9. doi:10.1556/JEP.6.2008.4.1

Wade, T. J., \& Walsh, H. (2008). Does the big-5 relate to jealousy, or infidelity reactions? Journal of Social, Evolutionary, and Cultural Psychology, 2, 133-143.

Wiederman, M. W., \& Kendall, E. (1999). Evolution, sex, and jealousy: Investigation with a sample from Sweden. Evolution and Human Behavior, 20, 121-128. doi:10.1016/S1090-5138(98)00046-4 